\title{
Body Height of Elite Basketball Players: Do Taller Basketball Teams Rank Better at the FIBA World Cup?
}

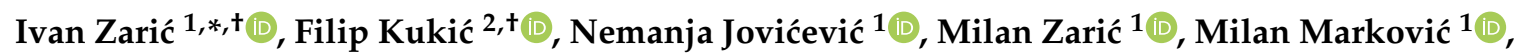 \\ Lazar Toskić $^{3}$ (i) and Milivoj Dopsaj ${ }^{1,4}$
}

1 Faculty of Sport and Physical Education, University of Belgrade, 11000 Belgrade, Serbia; jovichevich@gmail.com (N.J.); info@licnitrener.com (M.Z.); mm_milanm@yahoo.com (M.M.); milivoj.dopsaj@fsfv.bg.ac.rs (M.D.)

2 Police Sports Education Center, Abu Dhabi 253, UAE; filip.kukic@gmail.com

3 Faculty of Sport and Physical Education, University of Priština, 38220 Kosovska Mitrovica, Serbia; lazartoskic@gmail.com

4 Institute for Sport, Tourism and Service, South Ural State University, 454080 Chelyabinsk, Russia

* Correspondence: info@ivanzaric.com; Tel.: +381-631-234-999

+ Authors contributed equally.

Received: 31 March 2020; Accepted: 23 April 2020; Published: 30 April 2020

\begin{abstract}
Body height is among the most important attributes of basketball players. Whether it differs among the basketball players who compete at the world basketball championship (FIBA-WC) is unknown. The aim of this study was to investigate the differences between the basketball players from the teams ranked 1-16 and those ranked below 16th place. The body heights of all players from the last three FIBA-WCs were collected and allocated according to the ranking at the FIBA-WC and analyzed by position in team. An independent sample t-test was conducted to analyze the difference in body height of players ranked 1-16 and players who ranked below 16th place. The players from the first 16 teams were significantly taller at three positions: point guards (Difference $=2.92 \mathrm{~cm}$, $p<0.05$ ), shooting guards (Difference $=2.16 \mathrm{~cm}, p<0.05$ ), and small forwards (Difference $=2.49 \mathrm{~cm}$, $p<0.01$ ). Body height seems to be an important factor for the performance of the basketball team at the FIBA-WC. Considering that all players at the FIBA-WC went through rigorous selection process to be in their national teams, body height of the higher-ranked players could be used as a reference value.
\end{abstract}

Keywords: performance modelling; selection; talent acquisition; anthropology; morphology

\section{Introduction}

Basketball has been among the most popular sports in the world [1] whereby the finals in basketball are the closing event of the Olympic games. It is a dynamic game where two teams of five players each run back and forth attacking and defending a basket set at the height of $3.05 \mathrm{~m}$. The game is characterized by high-intensity intermittent runs, often requiring planned or unpredictable changes of direction, a variety of specific technical skills and well-developed jumping ability [2-4]. Thus, a player's achievement and success depends on physical abilities, physiological profile, mental abilities and tactical skills as well as on their anthropometric characteristics such as body height and body weight [5-8]. However, considering the height of the basket and that the winner is who scores more baskets, body height and weight have had the highest priority during the selection process and when establishing an in-court position $[9,10]$.

When investigating the differences in high level basketball players, Pehar et al. [7] found that players from the first division were significantly taller than the players from the second division. Furthermore, Garcia-Gil et al. [11] conducted regression analysis and found that body height was among 
the main predictors of performance index rating among elite female basketball players. Moreover, authors reported that the performance index rating correlated with the arm span and contracted arm perimeter. This could be also attributed to body height as taller people normally have longer hands, which reflects in longer arm span [12]. These characteristics are of importance in basketball game during jumping (i.e., rebounding and blocking), defending the space (i.e., covers wider and higher space), and shooting or dunking (i.e., over shorter players). Thus, body height provides the advantage in every aspect of the game [13].

Although the evidence suggests that teams with taller players may have better results, the existing studies mostly covered individual national basketball leagues. For the world cup (FIBA-WC), national teams select only the 12 best players that the country has. Moreover, the countries need to qualify for the world championship as strictly defined number of countries can participate. Accordingly, it could be assumed that those players who come to the FIBA-WC are the most elite in their countries and in the world. The competition system at FIBA-WC was set by International Basketball Federation (Fédération Internationale de Basketball [FIBA]). It consists of group phase and knockout phase. In a group phase at 2010 and 2014 FIBA-WC, six teams within one group played between each other and the best two teams from each group went into the knockout phase. At 2019 FIBA-WC, four teams in eight groups played against each other in the first group phase and two teams from each group went to second group phase. The second group phase consisted of four groups with four teams each and again two teams from each group went to knockout phase. The knockout phase means that every game until the end of the championship is played by the rule who win goes further into competition, until the last final game where two best teams play for the first place. Considering the nature of the knockout phase and the quality of teams that entered, where the winner can be any team, it could be assumed that the teams from the knockout phase are in some characteristics better than the teams that did not pass to this phase.

Considering this, the question arises whether the players from better ranked teams (i.e., knockout phase) are significantly taller than those whose teams ranked lower (i.e., qualified but did not pass to knockout phase). Therefore, this study aimed to evaluate if the teams from the knockout phase of the world basketball championship were significantly taller that the teams who did not enter the knockout phase. It is hypothesized that the teams and players who went through the first phase of FIBA-WC are significantly taller than those drop-off the competition in earlier stages. This would provide a position-specific body height model of the players from the teams that ranked higher at the FIBA-WC.

\section{Materials and Methods}

\subsection{Participants}

A retrospective analysis of body height for 960 elite basketball players from national basketball teams that competed at the last three (2010, 2014, and 2019) FIBA-WC. Body heights were obtained from the official web page of International Basketball Federation (Fédération Internationale de Basketball [FIBA]). Twenty-four teams competed at the 2010 and 2014 FIBA-WC, while the rules were changed for the 2019 where 32 teams were allowed to compete. The study is conducted in accordance with the Helsinki declaration regarding the ethical principles for medical research involving human subjects [14]. The study design was approved by the Ethical Board (number 484-2) of the Faculty of Sport and Physical Education, University of Belgrade, Belgrade, Serbia.

\subsection{Procedures}

National teams provided body heights of players to FIBA with registration of the team. How each team obtained body heights of their players could not be defined for this research. However, considering the importance of competition such as the FIBA-WC, it is reasonable to assume that the professionals who did the measurements provided accurate and reliable data. The teams from three FIBA-WCs were divided into two groups according to their ranking. The first group included the teams 
that passed the group phase at 2010 and 2014 FIBA-WC and the first group phase at 2019 FIBA-WC. These were the teams ranked from first to 16th place and this group was named 1-16 and had mean age $29.3 \pm 2.7$ years. At the 2010 and 2014 FIBA-WC, after the first group phase teams entered into the knockout phase, while in 2019 after the first group phase 16 teams entered into second group phase and eight teams entered the knockout phase. This difference occurred due to the change of rules as there were eight teams more at 2019 than at the 2010 and 2014 FIBA-WCs. However, considering that all teams had to go through the prequalification for the FIBA-WC and then through the first group phase of the FIBA-WC, it could be considered that the 16 teams that passed these stages were a homogenous group, thereby had players with similar skills and body characteristics. The second group $(16>)$ consisted of teams that did not pass the group phase of the competition and therefore were ranked below the 16th place. The mean age of this group was $28.9 \pm 2.8$ years. Although all teams that qualified to the FIBA-WC consist of rigorously selected and professionally trained athletes, it could be assumed that those who do not pass the first group phase are to some degree different in some characteristics compared to those who do pass it. For each group, body height was analysed relative to a player's position in the team and compared between the groups. The positions of players (point guard, shooting guard, small forward, power forward and center) were also collected from the FIBA web page, where each player has a profile with information about the position. For guards and forwards, whose position was not defined precisely (i.e., point or shooting guard and small or power forward) at the web page, authors conducted the video analysis of two to three different game plays [15] following procedures explained elsewhere [16]. The rationale was to determine if the point guards, shooting guards, small forwards, power forwards and centers from the 1-16 group were taller than those below the top 16 group.

\subsection{Statistical Analyses}

The statistical analyses were conducted using the Microsoft Excel and Statistical Package for Social Sciences (SPSS, version 22.0). The data were analysed descriptively for mean, standard deviation (SD), minimum (MIN), maximum (MAX), coefficient of variation (CV\%), and $95 \%$ confidence interval (95\% $\mathrm{CI})$. The Kolmogorov-Smirnov test was used to evaluate the normality of distribution. The differences between the groups were analysed by an Independent sample t-test, with the significance level set at $p<0.05$. The parametric test was chosen because the sample size was large enough and non-parametric tests in large studies may provide answers to the wrong question $[17,18]$. The Cohen's effect sizes were calculated for the magnitude of differences between the groups [19] using the formula: $\left(\mathrm{M}_{2}-\mathrm{M}_{1}\right) / \mathrm{SD}$, where $\mathrm{M}_{1}$ and $\mathrm{M}_{2}$ were the means of the groups, while $S D$ was a pooled standard deviation of compared groups. The magnitudes of differences were defined as small $=0.2-0.5$, moderate $=0.5-0.8$, and large $\geq 0.8$. The body height model of the most elite players was analysed descriptively and the range was presented in quartiles.

\section{Results}

The descriptive statistics for each position at the three FIBA-WC are shown in Table 1. Considering the whole sample, the mean body height for each position across all three competitions. Kolmogorov-Smirnov test that data at each position was normally distributed, with minimal $p=0.200$. 
Table 1. Body height of basketball players from three FIBA-WCs relative to position in team.

\begin{tabular}{|c|c|c|c|c|c|c|c|c|c|}
\hline \multirow{7}{*}{$\begin{array}{l}\text { World Basketball } \\
\text { Cup } 2010\end{array}$} & \multirow{2}{*}{ Positions } & \multirow{2}{*}{$\mathbf{N}$} & \multirow{2}{*}{ Mean (cm) } & \multirow{2}{*}{ SD } & \multirow{2}{*}{ CV\% } & \multirow{2}{*}{ Min } & \multirow{2}{*}{$\operatorname{Max}$} & \multicolumn{2}{|c|}{$95 \%$ CI } \\
\hline & & & & & & & & Lower & Upper \\
\hline & 1-Point guard & 30 & 189 & 5 & 3 & 178 & 199 & 187 & 191 \\
\hline & 2-Shooting guard & 91 & 192 & 6 & 3 & 176 & 206 & 191 & 193 \\
\hline & 3-Small forward & 82 & 202 & 4 & 2 & 192 & 213 & 201 & 203 \\
\hline & 4-Power forward & 20 & 205 & 3 & 2 & 198 & 211 & 204 & 207 \\
\hline & 5-Center & 65 & 210 & 5 & 2 & 198 & 222 & 209 & 211 \\
\hline \multirow{7}{*}{$\begin{array}{l}\text { World Basketball } \\
\text { Cup } 2014\end{array}$} & \multirow[b]{2}{*}{ Positions } & \multirow{2}{*}{$\mathbf{N}$} & \multirow{2}{*}{ Mean (cm) } & \multirow{2}{*}{ SD } & \multirow{2}{*}{$\mathrm{CV} \%$} & \multirow[b]{2}{*}{ Min } & \multirow{2}{*}{ Max } & \multicolumn{2}{|c|}{$95 \%$ CI } \\
\hline & & & & & & & & Lower & Upper \\
\hline & 1-Point guard & 47 & 188 & 6 & 3 & 170 & 198 & 186 & 189 \\
\hline & 2-Shooting guard & 70 & 192 & 6 & 3 & 180 & 204 & 191 & 194 \\
\hline & 3-Small forward & 67 & 201 & 5 & 3 & 189 & 213 & 200 & 202 \\
\hline & 4-Power forward & 48 & 205 & 4 & 2 & 198 & 215 & 204 & 207 \\
\hline & 5-Center & 56 & 210 & 4 & 2 & 200 & 218 & 209 & 211 \\
\hline \multirow{7}{*}{$\begin{array}{l}\text { World Basketball } \\
\text { Cup } 2019\end{array}$} & \multirow[b]{2}{*}{ Positions } & \multirow[b]{2}{*}{$\mathbf{N}$} & \multirow[b]{2}{*}{ Mean (cm) } & \multirow[b]{2}{*}{ SD } & \multirow[b]{2}{*}{$\mathrm{CV} \%$} & \multirow[b]{2}{*}{ Min } & \multirow[b]{2}{*}{ Max } & \multicolumn{2}{|c|}{$95 \% \mathrm{CI}$} \\
\hline & & & & & & & & Lower & Upper \\
\hline & 1-Point guard & 67 & 188 & 6 & 3 & 176 & 201 & 187 & 190 \\
\hline & 2-Shooting guard & 90 & 192 & 5 & 3 & 179 & 209 & 191 & 193 \\
\hline & 3-Small forward & 91 & 201 & 5 & 2 & 189 & 211 & 200 & 202 \\
\hline & 4-Power forward & 59 & 205 & 3 & 2 & 195 & 210 & 204 & 205 \\
\hline & 5-Center & 77 & 209 & 5 & 2 & 197 & 222 & 208 & 210 \\
\hline
\end{tabular}

However, once split into groups relative to the team ranking, the body height of point guards, shooting guards, and small forwards from the teams ranked 1-16 were significantly higher than the height of those ranked below 16th place (Table 2). The body height of power forwards and centers were similar, regardless of the team ranking. Moreover, the analysis of the effect sizes revealed a moderate to large magnitude of difference between the groups (Figure 1), whereby the biggest difference occurred at the position of small forward. Although the observed difference in height was not statistically significant in power forwards, the effect size analysis revealed the difference of small magnitude (Figure 1).

Table 2. Differences in body height of players from the first 16 teams and below the $16^{\text {th }}$ place, relative to position in team.

\begin{tabular}{lccc}
\hline \multirow{2}{*}{\multicolumn{1}{c}{ Positions }} & Ranking (1-16) & Ranking (below 16) & \multirow{2}{*}{ Mean Difference } \\
\cline { 2 - 3 } & Mean \pm SD & Mean \pm SD & \\
\hline 1-Point guard & $189 \pm 5 \mathrm{~cm}$ & $186 \pm 4 \mathrm{~cm}$ & $2.92^{*}$ \\
2-Shooting guard & $193 \pm 3 \mathrm{~cm}$ & $191 \pm 3 \mathrm{~cm}$ & $2.16^{*}$ \\
3-Small forward & $202 \pm 3 \mathrm{~cm}$ & $200 \pm 3 \mathrm{~cm}$ & $2.49^{* *}$ \\
4-Power forward & $206 \pm 3 \mathrm{~cm}$ & $205 \pm 3 \mathrm{~cm}$ & 0.64 \\
5-Center & $210 \pm 4 \mathrm{~cm}$ & $209 \pm 3 \mathrm{~cm}$ & 0.67 \\
\hline
\end{tabular}

* Significant at $p<0.05,{ }^{* *}$ Significant at $p<0.01$. 


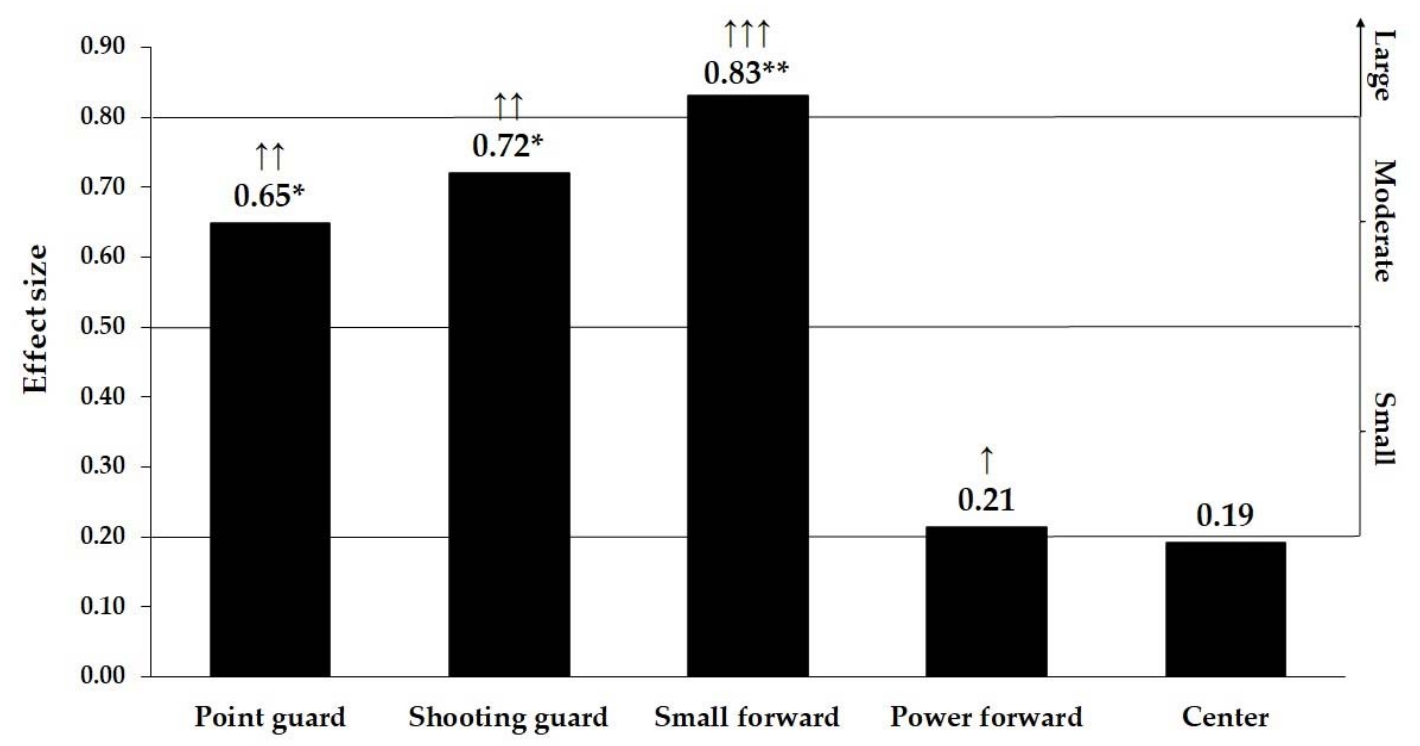

Figure 1. The size of the difference in body height between the teams of different ranking relative to position in team. ${ }^{*}$ Significant at $p<0.05,{ }^{* *}$ Significant at $p<0.01, \uparrow$ - small effect size, $\uparrow \uparrow$ 一moderate effect size, $\uparrow \uparrow \uparrow$ - large effect size.

Finally, considering that the heights of the 1-16 group were significantly higher, the descriptive statistics and quartile analysis are presented in Table 3.

Table 3. Descriptive statistics for each position for the teams that ranked 1-16.

\begin{tabular}{|c|c|c|c|c|c|c|c|c|}
\hline \multirow{2}{*}{ Positions } & \multirow{2}{*}{ Mean (cm) } & \multirow{2}{*}{ SD } & \multirow{2}{*}{$\mathrm{CV} \%$} & \multirow{2}{*}{ Min } & \multirow{2}{*}{$\operatorname{Max}$} & \multicolumn{3}{|c|}{ Quartiles } \\
\hline & & & & & & 25th & 50th & 75 th \\
\hline 1-Point guard & 189 & 5 & 3 & 178 & 199 & 185 & 190 & 192 \\
\hline 2-Shooting guard & 193 & 3 & 2 & 185 & 200 & 191 & 194 & 196 \\
\hline 3-Small forward & 202 & 3 & 2 & 194 & 210 & 200 & 202 & 204 \\
\hline 4-Power forward & 206 & 3 & 1 & 200 & 212 & 204 & 206 & 208 \\
\hline 5-Center & 210 & 4 & 2 & 200 & 216 & 208 & 210 & 212 \\
\hline All positions & 200 & 9 & 4 & 178 & 216 & 198 & 200 & 202 \\
\hline
\end{tabular}

\section{Discussion}

The aim of this study was to investigate if players from the teams ranked 1-16 were taller than players from the teams ranked below the 16th place, whereby differences in body height were investigated at each position. The main findings of this study indicate that teams with taller players on certain positions were ranked higher at the FIBA-WC. Namely, point guards, shooting guards, and small forwards of the first 16 teams were significantly taller than the players at the same position from the teams ranked below the 16th place. The obtained differences were small to large in magnitude, indicating the importance of body height in the selection process for the elite level of play.

The descriptive statistics consistently showed that starting from the position of point guard towards center, body height gradually increases. Each position has a specific set of tasks that in a large measure determine the body height of the players. For example, point guards are playmakers who dribble the ball the most. They are chased by defenders in order to disrupt the planned action, which is why they need to be quick and agile with remarkable ball control. High proficiency in agility while dribbling the ball under pressure allows them to focus to what is happening on the court so they can employ their teammate. In that regard, players with lower center of body mass are well suited to quickly accelerate, decelerate and possess good agility. Thus, point guards are usually somewhat shorter (although taller comparing to general adult male population [20-22]) than the other positions. 
Positions of shooting guards and small forwards have a lot of running tasks without the ball as they are opening or closing the space for the action to be completed, whereby shooting guards may move to the position of point guard if needed. Thus, although the shooting guards and small forwards are both taller than the point guards are, the shooting guards are shorter than the small forwards. Finally, power forwards and centers are tall and strong, ready to block the player or shoot, or jump for the ball under the basket (centers) or little further from the basket (power forwards). Additionally, when close to the basket they often play in close contact, pushing the opponent towards (offence) or off (defense) the basket, where the height and body weight have been advantage.

The results of the t-test are in accordance with previous studies that found body height be a significant predictor of basketball performance $[4,5,7]$. However, given that the success in basketball performance includes multiple factors whose magnitudes of influence may vary between players, it is hard to precisely define the magnitude to which the body height contributes to it. The importance of the height reflects in the fact that the players at the positions of point guards, shooting guards, and small forwards from the teams ranked first to 16th place were significantly higher than the players on the same positions who ranked below the 16th place. In addition, there was no significant difference in the body height of centers and power forwards, regardless of the team ranking, indicating that all national teams that qualified to the FIBA-WC selected the tallest centers from their countries. Typically, these are people who are in the highest percentiles or extremes of the population and they do not differ among themselves, regardless of the origin [20,21]. The practical advantage of tall players reflects in high blocking reach, wide space covered by arm span, high body weight and absolute strength, which all contribute to successful one-on-one play under the 3.05-m basket [23]. In a basketball game, the main jobs of center and power forwards are screens, blocking, collecting the balls (rebounds), and scoring under the basket, whereby power forwards often shoot very effectively from the distance as well. Indeed, some centers and power forwards (very few) move extraordinarily and do more than previously stated, but this only additionally strengthens the importance of the related body height and dimensions as these are usually hardly stoppable players who fill all the columns of the statistics (i.e., often score triple-double). In that regard, the results suggest that even among point guards, shooting guards, and small forwards of a similar skill level, those who are taller are a better fit for the more successful teams (i.e., perform better).

It could be argued that they are physically more dominant in one-on-one play offensively and defensively, that they have higher ball releasing point while shooting or in defensive jumping, and their arm span may cover wider space when guarding the space. When a player is covered by an aggressive defender, his aim is to perform the shot at the highest possible release point. The two-legged jump shot may amount to over $70 \%$ of all the shots during a game, whereby greater performance in executing the jump shot depends on the height at which the ball is released [13]. Thus, a taller point guard, shooting guard, and small forward may have advantage both ways, higher releasing point or higher reach while blocking the shot. Note that the first four players in the history of NBA by number of triple-doubles are point guards whose heights were 191-206 cm. Considering the tactical standpoint, after the screen, point guards, shooting guards or small forwards often need to defend power forwards and centers. Coaches may try to exploit the "weakness" of the opposing team with shorter guards or small forwards by frequently using pick-and-roll when centers or power forwards would play one-on-one against significantly shorter players. Similarly, when power forwards are good at shooting from distance, they tend to play pick-and-pop, which may be more comfortable if they are taller than the player in defense. In contrast, taller players in defense may have higher chances to be more successful when defending the opponents. For example, it would not be the same if the point guard of $180 \mathrm{~cm}$ defends the power forward of $204 \mathrm{~cm}$ after pick-and-pop as it would be if point guard is $195 \mathrm{~cm}$. In addition, a small forward of $205 \mathrm{~cm}$ would have advantage in low post play against the small forward of $198 \mathrm{~cm}$, which a coach could tactically exploit by setting the actions so the taller small forward has the space to play offensively more often by either shooting over the defendant or pushing him under the basket. 
In addition, taller players with longer extremities exit the off-ball screen very far, which provides them with longer time to shot, which may contribute to shooting accuracy.

From the quartile analysis of body height, overlapping could be observed between the positions. It seems that some point guards and shooting guards may have the same body height, thus play either position if they are also skilled for it; these positions may belong to the first body height cluster. The body height of taller small forwards overlaps with shorter power forwards, indicating that skilled players on these positions of similar body height may be used in the game on both positions, depending on the team tactics. This could be the second body height cluster. Similarly, body height of taller power forwards overlaps with shorter centers, which indicates that players on these two positions who have similar body height and adequate skill level can replace each other in the game if needed, forming the third body height cluster. Considering this, it could be concluded that at each position could be divided into three subclassifications, short, average, and tall. Short point guards $(<185 \mathrm{~cm})$, average point guards $(185-191 \mathrm{~cm})$, tall point guards $(\geq 192 \mathrm{~cm})$; short shooting guards $(<191 \mathrm{~cm})$, average shooting guards (191-195 cm), and tall shooting guards ( $\geq 196 \mathrm{~cm})$; short small forwards $(<200 \mathrm{~cm})$, average small forwards $(200-203 \mathrm{~cm})$, and tall small forwards $(\geq 204 \mathrm{~cm})$; short power forwards $(<204 \mathrm{~cm})$, average power forwards $(204-207 \mathrm{~cm})$ and tall power forwards $(\geq 208 \mathrm{~cm})$; short centers $(<208 \mathrm{~cm})$, average centers $(208-211 \mathrm{~cm})$, and tall centers $(\geq 212 \mathrm{~cm})$.

This study is not without limitations. Body height certainly is not the only factor important in talent acquisition and the selection process, nor could this study define whether body height is the most important factor. In that regard, the inclusion of variables such as players' age, body mass, body composition (i.e., percent skeletal muscle mass and body fat), physical abilities and specific basketball performance should be included for a more comprehensive analysis. However, the study clearly shows that body height is an important factor for teams ranking at FIBA-WC, thus providing the guidance to talent acquisition specialists and coaches.

Considering this, body height could be considered an important factor of success in basketball and, given that the players from the first 16 teams were significantly taller, their body height could be used as the reference values for the selection. This is further reinforced by the fact that the average height of the players from the National Basketball Association (NBA) is the same $(200.6 \mathrm{~cm})$ as of the average height of the payers from the first 16 teams [24]. Furthermore, the average height of the Spain national basketball team for the 2008 Olympics was $199.2 \mathrm{~cm}$, while the average body height of the best Serbian national league in 2007 was $199.5 \pm 7.4 \mathrm{~cm}$ [24]. It is of note that the best players from each of the mentioned leagues are normally the representatives of their countries on the FIBA-WC. Moreover, the players at the FIBA-WC are already rigorously selected by professional peers such as coaches and scouts. Therefore, the results obtained in this study seem to accurately describe the body height of the most elite basketball players in the world, thereby defines the reference norms for the player selection. This may have practical implications in modeling a successful basketball team and player positioning.

\section{Conclusions}

The body height of basketball players seems to play the major role in their overall performance at all positions. It could be concluded that, among the point guards, shooting guards, and small forwards of the same basketball knowledge (i.e., tactics) and skill, those who are taller perform better. On the other hand, when it comes to power forwards and especially centers who are typically chosen for their height, those who possess better basketball knowledge and skill perform better. Therefore, considering that body height is genetically predetermined and cannot be altered by training, it needs to be the part of selection process and talent acquisitioning for the elite level of basketball. This does not necessarily mean automatic exclusion of shorter players based on height. If they perform as same as or better than the taller player at the same position and contribute to the overall team performance to a larger extent, body height should not be the limiting factor. However, reference values for body height set based on the data from the elite basketball players of the world provide a valid body height model of high performers at each position within the team. In addition, it provides an insight into body 
height clusters that address possible overlapping of players at different positions. Although in practice coaches sometimes use the same player in different positions (i.e., shooting guard replacing point guard), body height has not been modeled so far in such a way to cover this space. Therefore, this study provides a formal and practical position-specific body height model of elite basketball players.

Author Contributions: Conceptualization, I.Z. and F.K.; methodology, I.Z. and F.K.; formal analysis, I.Z. and F.K.; investigation, N.J. and M.Z.; writing—original draft preparation, I.Z. and F.K.; writing-review and editing, I.Z. and F.K.; visualization, F.K. and M.M.; supervision, M.D. and L.T. All authors have read and agreed to the published version of the manuscript.

Funding: This research received no external funding.

Conflicts of Interest: The authors declare no conflict of interest.

\section{References}

1. Jakovljevic, S.; Macura, M.; Radivoj, M.; Jankovic, N.; Pajic, Z.; Erculj, F. Biological maturity status and motor performance in fourteen-year-old basketball players. Int. J. Morphol. 2016, 34, 637-644. [CrossRef]

2. Stojanović, E.; Stojiljković, N.; Scanlan, A.T.; Dalbo, V.J.; Berkelmans, D.M.; Milanović, Z. The activity demands and physiological responses encountered during basketball match-play: A systematic review. Sports Med. 2018, 48, 111-135. [CrossRef] [PubMed]

3. Ferioli, D.; Rampinini, E.; Bosio, A.; Torre, A.L.; Azzolini, M.; Coutts, A.J. The physical profile of adult male basketball players: Differences between competitive levels and playing positions. J. Sports Sci. 2018, 36, 2567-2574. [CrossRef] [PubMed]

4. Zarić, I.; Dopsaj, M.; Marković, M. Match performance in young female basketball players: Relationship with laboratory and field tests. Int. J. Perform. Anal. Sport 2018, 18, 90-103. [CrossRef]

5. Cui, Y.; Liu, F.; Bao, D.; Liu, H.; Zhang, S.; Gómez, M.-Á. Key anthropometric and physical determinants for different playing positions during National Basketball Association draft combine test. Front. Psychol. 2019, 10. [CrossRef]

6. Ostojic, S.M.; Mazic, S.; Dikic, N. Profiling in basketball: Physical and physiological characteristics of elite players. J. Strength Cond. Res. 2006, 20, 740-744. [CrossRef]

7. Pehar, M.; Sekulic, D.; Sisic, N.; Spasic, M.; Uljevic, O.; Krolo, A.; Milanovic, Z.; Sattler, T. Evaluation of different jumping tests in defining position-specific and performance-level differences in high level basketball players. Biol. Sport 2017, 34, 263-272. [CrossRef]

8. Zarić, I.; Dopsaj, M.; Marković, M.; Zarić, M.; Jakovljević, S.; Berić, D. Body composition characteristics measured by multichannel bioimpedance in young female basketball players: Relation with match performance. Int. J. Morphol. 2020, 38, 328-335. [CrossRef]

9. Dezman, B.; Trninić, S.; Dizdar, D. Expert model of decision-making system for efficient orientation of basketball players to positions and roles in the game-empirical verification. Coll. Antropol. 2001, 25, 141-152.

10. Vaquera, A.; Santiago, S.; Gerardo, V.J.; Carlos, M.J.; Vicente, G.-T. Anthropometric characteristics of Spanish professional basketball players. J. Hum. Kinet. 2015, 46, 99-106. [CrossRef]

11. Garcia-Gil, M.; Torres-Unda, J.; Esain, I.; Duñabeitia, I.; Gil, S.M.; Gil, J.; Irazusta, J. Anthropometric parameters, age, and agility as performance predictors in elite female basketball players. J. Strength Cond. Res. 2018, 32, 1723-1730. [CrossRef] [PubMed]

12. Popović, S. Arm-span measurement as an alternative estimation of true height in Montenegrin young adults of both sexes: A national survey. Anthropol. Noteb. 2018, 15, 53-67.

13. Struzik, A.; Pietraszewski, B.; Zawadzki, J. Biomechanical analysis of the jump shot in basketball. J. Hum. Kinet. 2014, 42, 73-79. [CrossRef] [PubMed]

14. Williams, J.R. The declaration of Helsinki and public health. Bull. World Health Organ. 2008, 86, 650-652. [CrossRef]

15. (86) FIBA-YouTube. Available online: https://www.youtube.com/user/FIBAWorld (accessed on 16 April 2020).

16. Ian, F.; Hughes, M. Notational Analysis of Sport: Systems for Better Coaching and Performance in Sport; Routledge: Abington, UK, 2004; ISBN 978-0-203-64195-8. 
17. Fagerland, M.W.; Sandvik, L. Performance of five two-sample location tests for skewed distributions with unequal variances. Contemp. Clin. Trials 2009, 30, 490-496. [CrossRef]

18. Fagerland, M.W. T-tests, non-parametric tests, and large studies-A paradox of statistical practice? BMC Med. Res. Methodol. 2012, 12, 78. [CrossRef]

19. Sullivan, G.M.; Feinn, R. Using effect size-Or why the P value is not enough. J. Grad. Med Educ. 2012, 4, 279-282. [CrossRef]

20. Fryar, C.D.; Gu, Q.; Ogden, C.L. Anthropometric reference data for children and adults: United States, 2007-2010. Vital. Health Stat. 2012, 11, 1-48.

21. Popovic, S. Local geographical differences in adult body height in montenegro. Montenegrin J. Sports Sci. Med. 2017, 6, 81-87.

22. NCD Risk Factor Collaboration (NCD-RisC) A century of trends in adult human height. Elife 2016, 5. [CrossRef]

23. Pojskic, H.; Separovic, V.; Muratovic, M.; Uzicanin, E. Morphological Differences of Elite Bosnian Basketball Players According to Team Position. Int. J. Morphol. 2014, 32, 690-694. [CrossRef]

24. Popovic, S.; Bjelica, D.; Jaksic, D.; Hadzic, R. Comparative study of anthropometric measurement and body composition between elite soccer and volleyball players. Int. J. Morphol. 2014, 32, 267-274. [CrossRef]

(C) 2020 by the authors. Licensee MDPI, Basel, Switzerland. This article is an open access article distributed under the terms and conditions of the Creative Commons Attribution (CC BY) license (http://creativecommons.org/licenses/by/4.0/). 